\title{
Radiation-Induced C-C Bond Cleavage in 1,2-Diarylethanes as Model Compounds of Coal, Part 3 \\ Pulse and Steady-State Radiolysis of 1,2-Di(9-anthryl)ethane in Organic Solvents $[1,2]$
}

\author{
Matthias W. Haenel ${ }^{\mathrm{a}, *}$, Udo-Burckhard Richter ${ }^{\mathrm{a}}$, Sonja Solar ${ }^{\mathrm{b}}$, Nikola Getoff ${ }^{\mathrm{b}}$,* \\ a Max-Planck-Institut für Kohlenforschung, Kaiser-Wilhelm-Platz 1, \\ D-45470 Mülheim a. d. Ruhr, Germany \\ b Institut für Theoretische Chemie und Strahlenchemie der Universität Wien, \\ Währingerstraße 38, A-1090 Wien, Austria \\ Dedicated to Prof. Dr. Dr. h.c. mult. Günther Wilke on the occasion of his 70 . birthday \\ Z. Naturforsch. 50b, 303-311 (1995); received September 15, 1994 \\ Radiolysis, C-C Bond Cleavage, 1,2-Diarylethane, Aluminium Hydride Reagent, \\ Transient Spectroscopy \\ 1,2-Di(9-anthryl)ethane (1,2-DAE) was used as a model for coal to study the $\mathrm{C}$ - $\mathrm{C}$ bond \\ cleavage of the ethano linkage in the radiolysis of solutions containing \\ $\mathrm{NaAlH}_{2}\left(\mathrm{OCH}_{2} \mathrm{CH}_{2} \mathrm{OCH}_{3}\right)_{2}\left[\mathrm{NaAlH}_{2}(\mathrm{OR})_{2}\right]$. Transient species were investigated by pulse \\ radiolysis of solutions of 1,2-DAE in THF, DME and toluene in the absence and the presence \\ of $\mathrm{NaAlH}_{2}(\mathrm{OR})_{2}$. In the presence of $\mathrm{NaAlH}_{2}(\mathrm{OR})_{2}$ stabilized, long-lived radical anion/so- \\ dium cation pairs of 1,2-DAE were generated even in the non-polar solvent toluene. The \\ reaction mechanisms differ substantially for solutions in the ether solvents (THF or DME) \\ and for solutions in toluene. Steady-state radiolysis $\left({ }^{60} \mathrm{Co} \gamma\right.$-rays) of solutions of 1,2 -DAE in \\ toluene containing $\mathrm{NaAlH}_{2}(\mathrm{OR})_{2}$ resulted in the $\mathrm{C}-\mathrm{C}$ bond cleavage of the ethano linkage. \\ This is attributed to the unstable dianion $\left(1,2-\mathrm{DAE}^{2-}, 2 \mathrm{Na}^{+}\right)$formed in two successive radi- \\ ation-induced reductions via $\left(1,2-\mathrm{DAE}^{--}, \mathrm{Na}^{+}\right)$. The resulting (9-anthryl)methyl carbanionic \\ fragments $\mathrm{C}_{14} \mathrm{H}_{9} \mathrm{CH}_{2}{ }^{-}, \mathrm{Na}^{+}$react with $\mathrm{AlH}(\mathrm{OR})_{2}$ generated in the process, to form the alum- \\ inate salts $\left[\mathrm{C}_{14} \mathrm{H}_{9} \mathrm{CH}_{2} \mathrm{AlH}(\mathrm{OR})_{2}{ }^{-}, \mathrm{Na}^{+}\right]$. From the aluminate salts, 9-methylanthracene (9- \\ MA) was obtained by hydrolysis in yields up to $65 \mathrm{wt} \%$.
}

\section{Introduction}

Bituminous coal consists mainly of organic material which has been formed from plant debris over a period of several hundred million years. The major part of the coal represents a macromolecular network in which aromatic, hydroaromatic and heteroaromatic structural units of, on the average, three (e.g. anthracene, phenanthrene) to five rings are crosslinked by short aliphatic chains and ether bonds [3, 4]. Hence any use of coal as a chemical feedstock requires extensive cleavage of $\mathrm{C}-\mathrm{C}$ bonds. The possibility of using gamma radiation for the degradation of the macromolecular coal has been recognized, and it has been found that the extractability by solvents increases and then decreases to some extent

\footnotetext{
* Reprint requests to Prof. Dr. M. W. Haenel or Prof. Dr. N. Getoff.
}

with increasing irradiation dose, when the solid coal was exposed to prolonged ${ }^{60} \mathrm{Co} \gamma$-radiation [5]. The effects have been explained with the interplay of degradation and crosslinking reactions, the former predominating at lower dose. On the other hand, it is well-known that radiolysis (electrons, gamma or Röntgen radiation) of polar organic solvents $(\mathrm{SH})$ such as tetrahydrofuran (THF) or dimethoxyethane (DME) generates solvated electrons $\mathrm{e}_{\mathrm{s}}^{-}$and "geminates" $\left(\mathrm{SH}^{++}, \mathrm{e}^{-}\right)$which in turn both can react with a dissolved aromatic substrate forming radical anions [6]. Radical anions are also intermediates in the reductive $\mathrm{C}-\mathrm{C}$ bond cleavage of 1,2-diarylethanes. These are cleaved with alkali metals in ether solvents at their ethano link forming two arylmethyl carbanionic fragments [7-11]. In the reductive alkylation of bituminous coal promoted by alkali metals, such a cleavage of benzylic $\mathrm{C}-\mathrm{C}$ bonds in 1,2-diarylethane structures is a major reaction path, so that specific bituminous coals can be degraded and converted into highly 
soluble products $[12,13]$. This was the background which prompted us several years ago to start a systematic investigation on the possibilities for a radiation-induced $\mathrm{C}-\mathrm{C}$ bond cleavage in 1,2-diarylethanes as model compounds of coal $[1,2,14$, $15]$. While the two previous parts of this series of papers have dealt with the pulse radiolysis and steady-state radiolysis of 1,2-di(1-naphthyl)ethane (1,2-DNE) [1] and 1,2-di(pyren-1-yl)ethane (1,2DPE) [2] in various organic solvents in the absence and the presence of alkali metal aluminium hydride reagents, the present paper describes our studies using 1,2-di(9-anthryl)ethane (1,2-DAE).
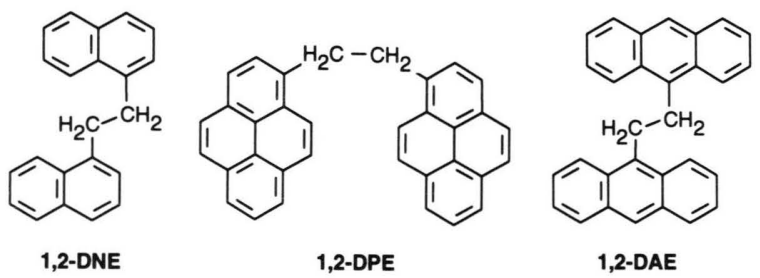

\section{Experimental}

\section{Preparation of the solutions}

Tetrahydrofuran (THF) and dimethoxyethane (DME) were distilled from lithium tetrahydridoaluminate under an argon atmosphere prior to use. Similarly, toluene was distilled from sodium potassium alloy. Sodium dihydrido-bis(2-methoxyethoxy)aluminate $\quad\left[\mathrm{NaAlH}_{2}\left(\mathrm{OCH}_{2} \mathrm{CH}_{2} \mathrm{OCH}_{3}\right)_{2}\right.$, referred to as $\mathrm{NaAlH}_{2}(\mathrm{OR})_{2}$ ] in $70 \%$ solution in toluene (Fluka) was used as obtained. For preparing its solutions in THF of DME, the toluene was removed by distillation in a vacuum. 9-Methylanthracene (9-MA, Aldrich) was dried in a vacuum and stored under argon.

1,2-Di(9-anthryl)ethane (1,2-DAE) was prepared from 9-anthraldehyde (Fluka) by reduction with lithium tetrahydridoaluminate in THF [16]. The greenish-yellow raw material obtained with $77 \%$ yield was twice recrystallized from toluene to yield light yellow needles (49\%) with m.p. $324^{\circ} \mathrm{C}$ (ref. [16] m.p. $\left.314-316{ }^{\circ} \mathrm{C}\right) .-{ }^{1} \mathrm{H}$ NMR $\left(\mathrm{CDCl}_{3}\right.$, $200 \mathrm{MHz}): \delta=8.40(\mathrm{~m}, 4 \mathrm{H}, 4,5-\mathrm{H}), 8.38(\mathrm{~s}, 2 \mathrm{H}$, $10-\mathrm{H}), 8.02(\mathrm{~m}, 4 \mathrm{H}, 1,4-\mathrm{H}), 7.50(\mathrm{~m}, 8 \mathrm{H}, 2,3,6,7-\mathrm{H})$, $4.06\left(\mathrm{~s}, 4 \mathrm{H},-\mathrm{CH}_{2}-\right)$. - MS $(70 \mathrm{eV}): m / z(\%)=$ $382(15) \quad\left[\mathrm{M}^{+}\right], 191(100) . \quad-$ UV/VIS (THF): $\lambda_{\text {max }}(\lg \varepsilon)=249 \mathrm{~nm}$ (5.28), 257 (5.28), 337 (3.69), 354 (3.99), 373 (4.28), 394 (4.39).

$$
\begin{array}{ccc}
\mathrm{C}_{30} \mathrm{H}_{22}(382.51) & \\
\text { Calcd } & \mathrm{C} 94.20 & \text { H } 5.80 \%, \\
\text { Found } & \text { C } 94.26 & \text { H } 5.97 \% .
\end{array}
$$

\section{Irradiation techniques}

Pulse radiolysis experiments were carried out on a $3 \mathrm{MeV}$ Van de Graaff accelerator (type K, High Voltage Engineering Co., Burlington, providing pulse lengths: $0.2-4 \mathrm{~ms}$ ) with an optical detection system (XBO Osram $450 \mathrm{~W}$ Xe-lamp, Zeiss $\mathrm{MM} / 2$ double monochromator, Hamamatsu R 955 photomultiplier) [17]. It was equipped for fully automatic registration of intermediates by use of a transient recorder (Tektronix $7612 \mathrm{D}$, formerly Biomation 8100) interfaced to minicomputers (Digital Equipment Corp.), which were used for processing, analysis and storage of the experimental data. For dosimetry, $\mathrm{N}_{2} \mathrm{O}$ saturated $10^{-2} \mathrm{~mol}$ $\mathrm{dm}^{-3}$ solutions of KSCN were irradiated and the optical density was monitored at $480 \mathrm{~nm}$ $\left[\mathrm{G}(\mathrm{SCN})_{2}{ }^{-}=6.12^{*}\right.$; at $480 \mathrm{~nm} e(\mathrm{SCN})_{2}{ }^{-}=$ $7580 \mathrm{dm}^{3} \mathrm{~mol}^{-1} \mathrm{~cm}^{-1}$ ] [18]. The absorbed dose** was corrected for the difference of density between dosimeter and solvent used.

The pulse radiolysis experiments were performed using air- and moisture-free solutions under an argon atmosphere at various concentrations of the substrate 1,2-DAE and $\mathrm{NaAlH}_{2}(\mathrm{OR})_{2}$. Each measured point of the transient absorption spectra shown represents a mean value from at least 5 individual determinations. The optical densities $(\mathrm{OD} / \mathrm{cm})$ were normalized to an absorbed dose of $10 \mathrm{~Gy}$ (1 krad). For steady-state irradiation, a $10 \mathrm{kCi}$ panorama ${ }^{60} \mathrm{Co}-\gamma$-source $(\mathrm{Nu}$ clear Engineering Ltd.) was used. The absorbed dose at each desired irradiation position was determined by using an aqueous solution of ferrous and cupric sulfate (ferrous-cupric dosimeter) as well as an aqueous solution of ferrous sulfate saturated with oxygen (Fricke dosimeter) [19, 20]. The dose rate was 4.0 to $16.7 \mathrm{kGy} \mathrm{h}^{-1}$.

\section{Spectroscopic and chemical analysis}

In order to obtain information on the existence of long-lived transients, a series of air-free toluene solutions of 9-MA and 1,2-DAE in the presence of excess $\mathrm{NaAlH}_{2}(\mathrm{OR})_{2}$ were $\gamma$-irradiated in suprasil

* G-value $=$ number of molecules produced per $100 \mathrm{eV}$ absorbed energy; to convert into SI-units ( $\mu \mathrm{mol} \mathrm{J}^{-1}$ ) multiply G-value by 0.10364 ;

** $100 \mathrm{rad}=1 \mathrm{~Gy}=6.24 \times 10^{15} \mathrm{eV} \mathrm{g}^{-1}$. 
quartz cells with $1 \mathrm{~cm}$ light path. The UV/VIS absorption spectra of the unirradiated and irradiated samples at various doses were compared (PerkinElmer UV/VIS spectrometer 554).

To aliquots of toluene solutions of 1,2-DAE, which had been irradiated in the presence of excess $\mathrm{NaAlH}_{2}(\mathrm{OR})_{2}$ under steady-state conditions, certain quantities of $n$-butanol were added to protonate carbanionic species formed and to decompose the excess of alkali metal aluminium hydrides. Subsequently, after a solution of $n$-tetradecane and $n$-docosane in toluene had been added as standards for GC-analysis, the mixtures were hydrolyzed with aqueous hydrochloric acid and extracted three times with $3 \mathrm{ml}$ quantities of toluene. After drying over anhydrous sodium sulphate, the toluene extracts were analyzed for 1,2-DAE and 9-MA by GC (Varian 3700, 20 m PS-428 FS capillary column, $100-300{ }^{\circ} \mathrm{C}$ with $8 \%$ min, on-column technique).

\section{Results and Discussion}

Pulse radiolysis

\section{1,2-DAE in THF, DME and Toluene}

Air-free solutions of $10^{-3}$ to $5 \times 10^{-4} \mathrm{~mol} \mathrm{dm}^{-3}$ 1,2-di(9-anthryl)ethane (1,2-DAE) in THF, DME, or toluene were used for the pulse radiolysis studies. Several series of experiments demonstrated that the transient absorption spectra do not differ essentially in THF and DME. For this reason only the transient spectra observed in $\operatorname{DME}(\mathrm{A})$ and toluene (B) are presented in Fig. 1. Spectrum (A) shows absorption maxima at 425, 610, 670 (shoulder) and $715 \mathrm{~nm}$. The different kinetic traces observed for the transient spectrum (A) at 430 and $720 \mathrm{~nm}$ (Fig. 1, inserts) reveal that at least two species must be involved. By comparison with spectra reported for the radical anions of anthracene and 9-methylanthracene [21], the broad absorption band between 550 and $800 \mathrm{~nm}$ with the maximum at $715 \mathrm{~nm}$ has to be attributed exclusively to the radical anion 1,2-DAE ${ }^{--}$. The absorption at $430 \mathrm{~nm}$, however, arises from the superposition of at least two, possibly also three species: a) the hydrogen adduct $1,2-\operatorname{DAE}(\mathrm{H})^{*}$ formed by protonation of the radical anion $1,2-\mathrm{DAE}^{--}$ through the protonated solvent cation $\mathrm{SH}\left(\mathrm{H}^{+}\right)$[reaction (5), below], b) the radical anion 1,2-DAE ${ }^{--}$, and c) possibly to some extent also the excited triplet state molecule ${ }^{3}(1,2-\mathrm{DAE})$. In our previous

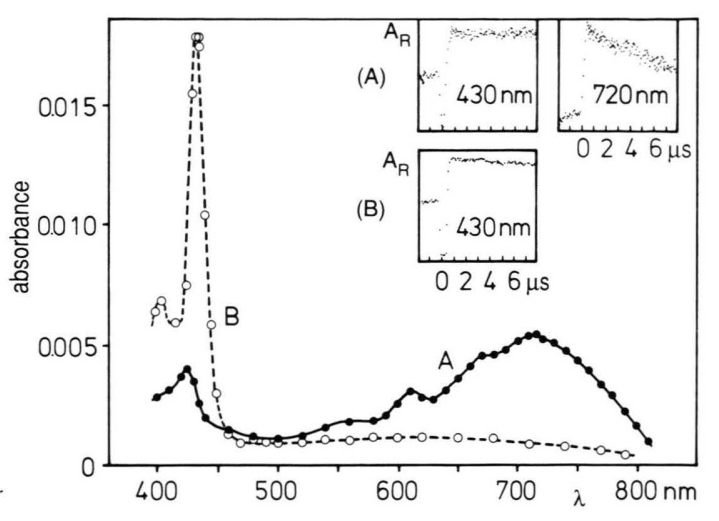

Fig. 1. Transient absorption spectra obtained from $5 \times 10^{-4} \mathrm{~mol} \mathrm{dm}^{-3} 1,2$-DAE in air-free DME [spectrum $\mathrm{A},(-)]$ and in toluene [spectrum $\mathrm{B},(\bigcirc)]$. The absorbances are normalized to $10 \mathrm{~Gy}$.

Inserts: Relative absorbance $\left(A_{R}\right)$ as a funcction of time $[\mu \mathrm{s}]$ at the absorption maxima at 430 and $720 \mathrm{~nm}$ for solutions (A) in DME and (B) in toluene.

pulse radiolysis studies performed with solutions of 1,2-DNE and 1,2-DPE in THF and DME, all these corresponding transients of both the aromatic substrates have also been observed $[1,2]$.

When toluene is used as the solvent [Fig. 1, spectrum (B)], a strong absorption maximum appears at $435 \mathrm{~nm}$ together with a weaker one at $405 \mathrm{~nm}$, but the spectrum shows almost no absorption between 550 and $800 \mathrm{~nm}$, the absorption range of 1,2-DAE ${ }^{--}$. The comparison with literature data of the $\mathrm{T}-\mathrm{T}$ absorption of anthracene [22] allows the assignment of the absorptions at 405 and $435 \mathrm{~nm}$ to ${ }^{3}(1,2$-DAE $)$ which is the only prevailing species formed in toluene. As indicated by the kinetic traces, the transients ${ }^{3}(1,2-\mathrm{DAE})$ formed in toluene have a longer lifetime than the short-lived radical anions formed predominantly in DME and THF [compare insert (B) at $430 \mathrm{~nm}$ with insert (A) at $720 \mathrm{~nm}$ in Fig. 1].

The formation of the transients observed in the radiolysis of solutions of aromatic substrates such as 1,2-DAE in organic solvents $\mathrm{SH}$ can be rationalized by the major reactions (1) to (12) which had been proposed previously [1, 2, 23]:

$$
\begin{aligned}
\mathrm{SH} \rightarrow W & \mathrm{SH}^{*}\left({ }^{1} \mathrm{SH},{ }^{3} \mathrm{SH}\right) \\
& \longrightarrow \mathrm{S}^{\cdot}+\mathrm{H}^{\cdot} \\
& \left.\longrightarrow \mathrm{SH}^{++}, \mathrm{e}^{-}\right] \text {(geminates) } \\
& \mathrm{SH}^{++}+\mathrm{e}_{\mathrm{s}}^{-} \text {(solvated electrons) }
\end{aligned}
$$




$$
\begin{aligned}
& \mathrm{SH}^{++}+\mathrm{SH} \rightarrow \mathrm{SH}\left(\mathrm{H}^{+}\right)+\mathrm{S} . \\
& 1,2-\mathrm{DAE}+\mathrm{e}_{\mathrm{s}}^{-} \rightarrow 1,2-\mathrm{DAE}^{--} \\
& 1,2-\mathrm{DAE}+\left[\mathrm{SH}^{++}, \mathrm{e}^{-}\right] \rightarrow 1,2-\mathrm{DAE}^{--}+\mathrm{SH}^{++} \\
& 1,2-\mathrm{DAE}^{\cdot-}+\mathrm{SH}\left(\mathrm{H}^{+}\right) \rightarrow 1,2-\mathrm{DAE}(\mathrm{H})^{\cdot}+\mathrm{SH} \\
& \text { (H-adduct) } \\
& 1,2-\mathrm{DAE}^{\cdot-}+\mathrm{SH}^{++} \rightarrow 1,2-\mathrm{DAE}^{*}\left[{ }^{1}(1,2-\mathrm{DAE}),\right. \\
& 3(1,2-\mathrm{DAE})]+\mathrm{SH} \\
& 1,2-\mathrm{DAE}^{--}+\mathrm{SH}\left(\mathrm{H}^{+}\right) \rightarrow \text { 1,2-DAE* }+\mathrm{SH}+1 / 2 \mathrm{H}_{2} \\
& 1,2-\mathrm{DAE}+\mathrm{SH}^{+} \rightarrow 1,2-\mathrm{DAE}^{++}+\mathrm{SH} \\
& \text { 1,2-DAE }{ }^{+}+1,2-\mathrm{DAE}^{--} \rightarrow 1,2-\mathrm{DAE}^{*}+1,2-\mathrm{DAE} \\
& 1,2-\mathrm{DAE}+{ }^{1} \mathrm{SH} \rightarrow{ }^{1}(1,2-\mathrm{DAE})+\mathrm{SH} \\
& 1,2-\mathrm{DAE}+{ }^{3} \mathrm{SH} \rightarrow{ }^{3}(1,2-\mathrm{DAE})+\mathrm{SH} \\
& { }^{1}(1,2-\mathrm{DAE}) \stackrel{\text { ISC }}{\longrightarrow}{ }^{3}(1,2-\mathrm{DAE})
\end{aligned}
$$

On radiolysis of the more polar ether solvents THF and DME (SH = THF, DME), the ionization reactions (1c) and (1d) prevail over the generation of the solvent excited-state molecules in reaction (1a), such that predominantly "geminates" $\left(\mathrm{SH}^{++}, \mathrm{e}^{-}\right)$and solvated electrons $\mathrm{e}_{\mathrm{s}}^{-}$are formed*. These in turn convert aromatic substrate via the consecutive reactions (2) to (5) to radical anions 1,2-DAE ${ }^{--}$and hydrogen adducts 1,2-DAE $(\mathrm{H})$, the major transients observed in THF and DME [spectrum (A) in Fig. 1]. However, the radical anions are short-lived, due to the rapid neutralization reactions [protonation (5) and electron transfer (6) and (7)] by the positively charged solvent counter ions, $\mathrm{SH}\left(\mathrm{H}^{+}\right)$or $\mathrm{SH}^{+}$, which are concomitantly generated by the radiolytic ionization process of the ether solvents $\mathrm{SH}$. On the contrary, in the non-polar hydrocarbon toluene the formation of "geminates" and solvated electrons $\mathrm{e}_{\mathrm{s}}{ }^{-}$is strongly disfavoured. The very reactive "thermalized" electrons $\mathrm{e}_{\mathrm{th}}{ }^{-}$, initially produced by radiolysis, recombine with the positive counterions $\mathrm{SH}^{+}(\mathrm{SH}=$ toluene $)$ rather than being further stabilized by solvation. As a consequence, when the solvent is toluene, solvent excited-state molecules $\mathrm{SH}^{*}\left({ }^{1} \mathrm{SH}\right.$ and $\left.{ }^{3} \mathrm{SH}\right)$ are the prevailing species formed in reaction (1a)*. Hence, the formation of the major transient ${ }^{3}(1,2-\mathrm{DAE})$, observed in the pulse radiolysis of 1,2-DAE in toluene solution [spectrum (B) in Fig. 1], can be easily rationalized

\footnotetext{
* For the very different yields of the primary radiolysis products of THF and toluene compare Table I and the discussion in ref. [2].
}

by energy transfer from electronically excited toluene and intersystem crossing [reactions (10) to (12)].

\section{1,2-DAE in THF, DME and toluene containing $\mathrm{NaAlH}_{2}(\mathrm{OR})_{2}$}

As already previously demonstrated $[1,2,15$, 24], alkali metal aluminium hydride reagents, e.g. $\mathrm{LiAlH}_{4}, \mathrm{NaAlH}_{4}$, or $\mathrm{NaAlH}_{2}(\mathrm{OR})_{2}$, can be used as scavengers for solvent radical cations $\mathrm{SH}^{++}$and solvent cations $\mathrm{SH}\left(\mathrm{H}^{+}\right)$which in the radiolytic ionization of the ether solvents THF and DME are generated concomitantly as the counterions to the solvated electrons $\mathrm{e}_{\mathrm{s}}{ }^{-}$. Hence, in the presence of such scavengers in excess $\left(>10^{-1} \mathrm{~mol} \mathrm{dm}^{-3}\right)$, solutions of aromatic substrates can be radiolytically reduced to form stable and long-lived radical anion alkali metal cation pairs. Preference has been given to $\mathrm{NaAlH}_{2}(\mathrm{OR})_{2}$ *, since this reagent offers the advantage of transparency and excellent solubility in various organic solvents, including toluene $[2,15,25]$.

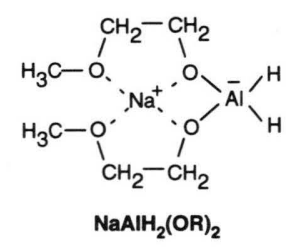

The transient absorption spectrum resulting from 1,2-DAE $\left(5 \times 10^{-4} \mathrm{~mol} \mathrm{dm}^{-3}\right)$ and $\mathrm{NaAlH}_{2}(\mathrm{OR})_{2}\left(1 \mathrm{~mol} \mathrm{dm}{ }^{-3}\right)$ in DME [Fig. 2, spectrum (A)] exhibits maxima at 400, 560, 610, 680 (shoulder) and $720 \mathrm{~nm}$. As it has been noticed already in the absence of $\mathrm{NaAlH}_{2}(\mathrm{OR})_{2}$, the transient spectra obtained from the pulse radiolysis of THF and DME solutions were almost identical. Except for a maximum at $400 \mathrm{~nm}$, showing a somewhat differing behaviour of its kinetics, the spectrum is assigned to stabilized, pure (1,2-

\footnotetext{
$+\mathrm{NaAlH}_{2}(\mathrm{OR})_{2}$ is strongly associated to higher aggregates in toluene solution ( $\mathrm{n}=5-17$ in dependence on concentration and temperature) and forms mainly dimers in THF [25]. The association can be rationalized by the complexation of the sodium cation through the 2 -methoxyethoxy substituents of the aluminate. The structure for $\mathrm{NaAlH}_{2}(\mathrm{OR})_{2}$ is simplified by showing the complexation with only one aluminate.
} 
$\mathrm{DAE}^{\cdot-}, \mathrm{Na}^{+}$) radical anion/sodium cation pairs which are formed in the presence of $\mathrm{NaAlH}_{2}(\mathrm{OR})_{2}$ according to reactions (1), (2) and (13) to (18) [2]:

$$
\begin{aligned}
& {\left[\mathrm{AlH}_{2}(\mathrm{OR})_{2}{ }^{-}, \mathrm{Na}^{+}\right] \rightarrow \mathrm{AlH}_{2}(\mathrm{OR})_{2}{ }^{-}+\mathrm{Na}^{+}} \\
& \mathrm{AlH}_{2}(\mathrm{OR})_{2}{ }^{-}+\mathrm{SH}\left(\mathrm{H}^{+}\right) \rightarrow \mathrm{AlH}(\mathrm{OR})_{2}+\mathrm{H}_{2}+\mathrm{SH} \\
& \mathrm{AlH}_{2}(\mathrm{OR})_{2}{ }^{-}+\mathrm{SH}^{+} \rightarrow \mathrm{AlH} \\
& (\mathrm{OR})_{2}+
\end{aligned}
$$

The absorbance of $\left(1,2-\mathrm{DAE}^{--}, \mathrm{Na}^{+}\right)$is about an order of magnitude higher than that of the 1,2-DAE ${ }^{-}$species, measured in the absence of $\mathrm{NaAlH}_{2}(\mathrm{OR})_{2}$ [spectrum (A), Fig. 1]. The kinetic traces [inserts (A), Fig. 2] show on the shorter time scale that the formation of $\left(1,2-\mathrm{DAE}^{--}, \mathrm{Na}^{+}\right)$is completed within 4 to $6 \mu \mathrm{s}$, and on the longer time scale that after a first very small decay the species are stable at least for several ms. Both effects, the drastic increase of the absorbance and the stability of the species, are attributed to the scavenger's capability of preventing effectively the decay reactions (6) and (7).

Using toluene as the solvent for 1,2-DAE and $\mathrm{NaAlH}_{2}(\mathrm{OR})_{2}$, spectrum (B) of Fig. 2 was obtained. It has the same structure as spectrum (A)

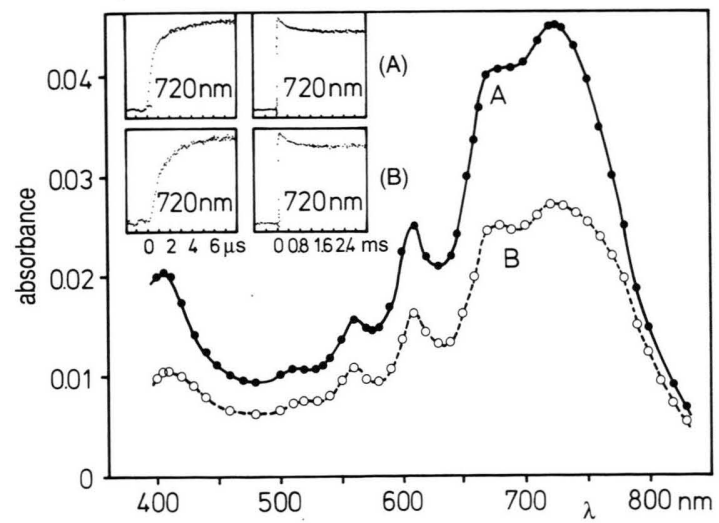

Fig. 2. Transient absorption spectra obtained from $5 \times 10^{-4} \mathrm{~mol} \mathrm{dm}^{-3} 1,2$-DAE in the presence of $1 \mathrm{~mol}$ $\mathrm{dm}^{-3} \mathrm{NaAlH}_{2}(\mathrm{OR})_{2}$ in DME [spectrum $\mathrm{A},(\mathbf{)})$ ] and in toluene [spectrum $\mathrm{B},(\mathrm{O})$ ] at about $25-30 \mu$ s after pulse. The absorbances are normalized to $10 \mathrm{~Gy}$.

Inserts: Relative absorbance as a function of time [ $\mu \mathrm{s}$ and $\mathrm{ms}$ ] at the absorption maximum at $720 \mathrm{~nm}$ for solutions $(\mathrm{A})$ in DME and (B) in toluene. observed in DME, but with only about half the absorbances. The kinetic traces of the inserts (B) resemble very closely those of (A) observed in DME. In contrast to the solution of 1,2-DAE in toluene without $\mathrm{NaAlH}_{2}(\mathrm{OR})_{2}$, where ${ }^{3}(1,2-\mathrm{DAE})$ was the major species formed [Fig. 1, spectrum (B)], the presence of $\mathrm{NaAlH}_{2}(\mathrm{OR})_{2}$ results in the complete quenching of the triplet absorption and the appearance of the absorption of the stabilized ion pairs $\left(1,2-\mathrm{DAE}^{--}, \mathrm{Na}^{+}\right)$.

In the radiolysis of toluene solutions ionic species such as "geminates" $\left[\mathrm{SH}^{+}, \mathrm{e}^{-}\right]$and free ions $\mathrm{SH}^{++}$and $\mathrm{e}_{\mathrm{s}}^{-}$represent, as already discussed, only a minor part of the transients, and excited-state molecules are the dominating species instead. Hence the reactions (13) to (18) certainly are not well-suited to rationalize the role $\mathrm{NaAlH}_{2}(\mathrm{OR})_{2}$ plays in the radiation-induced formation of stabilized aromatic radical anion/sodium cation pairs in toluene solutions. Based on our former extensive studies using pyrene as the substrate [2], the following reactions (19) to (22) and (16) are proposed:

$$
\begin{aligned}
& \mathrm{TOL}^{*}+\left[\mathrm{Na}^{+}, \quad \mathrm{AlH}_{2}(\mathrm{OR})_{2}{ }^{-}\right] \rightarrow\left(\mathrm{TOL}^{--}, \mathrm{Na}^{+}\right)+ \\
& \mathrm{AlH}_{2}(\mathrm{OR})_{2}{ }^{\circ} \\
& \left(\mathrm{TOL}^{--}, \mathrm{Na}^{+}\right)+1,2-\mathrm{DAE} \rightarrow \mathrm{TOL}+\left(1,2-\mathrm{DAE}^{--}, \mathrm{Na}^{+}\right) \\
& \mathrm{TOL}^{*}+1,2-\mathrm{DAE} \rightarrow \mathrm{TOL}+1,2-\mathrm{DAE}^{*} \\
& 1,2-\mathrm{DAE}^{*}+\left[\mathrm{Na}^{+}, \mathrm{AlH}_{2}(\mathrm{OR})_{2}{ }^{-}\right] \rightarrow\left(1,2-\mathrm{DAE}^{--}, \mathrm{Na}^{+}\right)+ \\
& \mathrm{AlH}_{2}(\mathrm{OR})_{2} \\
& 2 \mathrm{AlH}_{2}(\mathrm{OR})_{2} \cdot 2 \mathrm{AlH}(\mathrm{OR})_{2}+\mathrm{H}_{2}
\end{aligned}
$$

The main feature of this mechanism is the reduction of electronically excited toluene TOL* $\left[{ }^{1}(\mathrm{TOL})\right.$ and $\left.{ }^{3}(\mathrm{TOL})\right]$ by $\mathrm{NaAlH}_{2}(\mathrm{OR})_{2}$ to give $\left(\mathrm{TOL}^{--}, \mathrm{Na}^{+}\right.$) which in turn acts as the reducing agent for 1,2-DAE [reactions (19) and (20)]. Additionally, or alternatively, the electronic excitation might first be transferred from toluene to 1,2-DAE by either singlet-singlet or triplettriplet energy transfer, the excited-state molecules 1,2-DAE* subsequently being reduced by $\mathrm{NaAlH}_{2}(\mathrm{OR})_{2}$ [reactions (21) and (22)]. Owing to their longer lifetimes, the excited triplet state molecules ${ }^{3}$ (TOL) and ${ }^{3}(1,2-\mathrm{DAE})$ are assumed to be reduced preferentially by $\mathrm{NaAlH}_{2}(\mathrm{OR})_{2}$ resulting in the formation of the radical anion/sodium cation pairs $\left(\mathrm{TOL}^{--}, \mathrm{Na}^{+}\right)$and $\left(1,2-\mathrm{DAE}^{--}, \mathrm{Na}^{+}\right)$. As in the scavenging mechanism [reactions (14) to (16)], $\mathrm{AlH}_{2}(\mathrm{OR})_{2}$, produced in the reduction of 
excited-state molecules to radical anions, is assumed to form the trivalent aluminium species $\mathrm{AlH}(\mathrm{OR})_{2}$ by loss of hydrogen [reaction (16)]. The energetics and some arguments in favour of this mechanism have been discussed previously [2].

\section{Steady-state radiolysis}

The pulse radiolysis experiments have demonstrated that radiolysis of solutions of 1,2-DAE in THF, DME, or toluene containing excess $\mathrm{NaAlH}_{2}(\mathrm{OR})_{2}$ generates the radical anion/sodium cation pairs $\left(1,2-\mathrm{DAE}^{--}, \mathrm{Na}^{+}\right)$. These are longlived in terms of the pulse radiolysis time scale, so that 1,2-DAE is expected to undergo radiationinduced cleavage of the central benzylic $\mathrm{C}-\mathrm{C}$ bond, similarly as it has been observed previously already in the case of 1,2-DNE [1] and 1,2-DPE [2]. In order to investigate the radiation-induced $\mathrm{C}-\mathrm{C}$ bond cleavage of 1,2-DAE, studies under steady-state irradiation were also performed. The solvent was restricted to toluene, since the ether solvents DME and especially THF had been found to be not completely inert under steady-state irradiations in the presence of alkali metal aluminium hydride reagents [1, 2]. In a first series of experiments, irradiations using a ${ }^{60} \mathrm{Co} \gamma$-source were followed by conventional UV/VIS spectroscopy. In a second series the final products obtained from 1,2-DAE were investigated.

\section{UV/VIS spectra}

In a quartz cuvette of $1 \mathrm{~cm}$ pathlength air-free solutions of $2 \times 10^{-4} \mathrm{~mol} \mathrm{dm}^{-3}$ 9-methylanthracene (9-MA) or $1 \times 10^{-4} \mathrm{~mol} \mathrm{dm}^{-3} 1,2$-DAE in toluene containing $1.0 \mathrm{~mol} \mathrm{dm}^{-3} \mathrm{NaAlH}_{2}(\mathrm{OR})_{2}$ were irradiated with a ${ }^{60} \mathrm{Co} \gamma$-source $\left(3.16 \mathrm{kGy} \mathrm{h}^{-1}\right)$ at room temperature. The UV/VIS spectra of the solutions were recorded at various time intervals simply by interrupting the irradiation and transferring the cuvette into the spectrometer. Fig. 3 compares typical spectra in the range $300-800 \mathrm{~nm}$ obtained for irradiation doses between 0 and $790 \mathrm{~Gy}$ (irradiation times between 0 and $15 \mathrm{~min}$ ).

Before irradiation both solutions in toluene were transparent to light of wavelengths $>410 \mathrm{~nm}$ and showed the well-structured p-band $\left(\right.$ or $\left.{ }^{1} \mathrm{~L}_{\mathrm{b}}\right)$ of the anthracene chromophor with the typical 4 sharp maxima at 332, 350, 368 and $389 \mathrm{~nm}$ in the
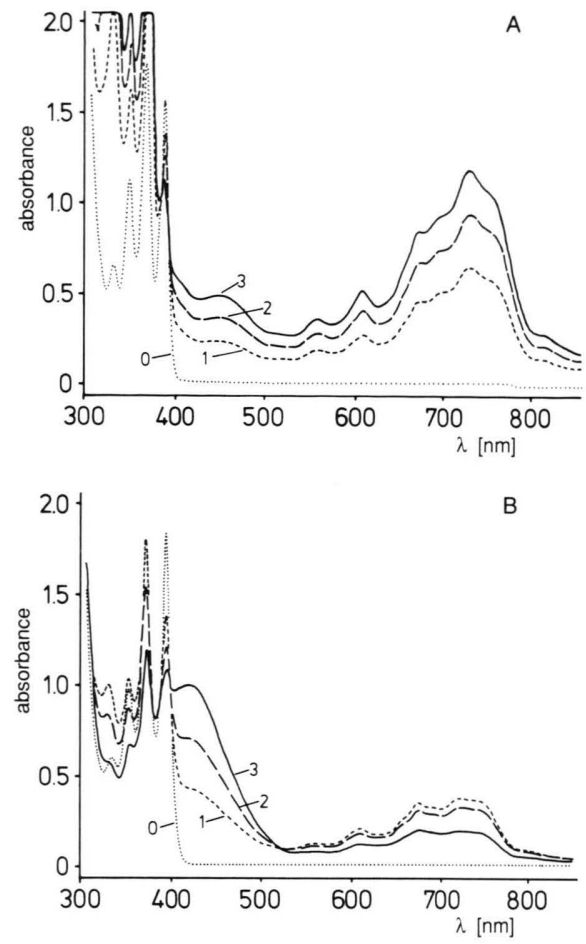

Fig. 3. UV/VIS spectra (pathlength $1 \mathrm{~cm}$ ) of solutions containing (A) 9-methylanthracene (9-MA) $\left(2 \times 10^{-4}\right.$ mol $\left.\mathrm{dm}^{-3}\right)$ and (B) 1,2-DAE $\left(1 \times 10^{-4} \mathrm{~mol} \mathrm{dm}^{-3}\right)$ together with $\mathrm{NaAlH}_{2}(\mathrm{OR})_{2}\left(1 \mathrm{~mol} \mathrm{dm}^{-3}\right)$ in toluene as a function of the ${ }^{60} \mathrm{Co} \gamma$-irradiation dose (dose rate 3.16 $\left.\mathrm{kGy} \mathrm{h}^{-1}\right)$. Applied dose [Gy]: 0, 0; 1, 370; 2, 580; 3, 790.

case of 9-MA [Fig. 3 (A)] and at 337, 354, 373 and $394 \mathrm{~nm}$ in the case of 1,2-DAE Fig. 3 (B)]. On irradiation of 9-MA in the presence of $\mathrm{NaAlH}_{2}(\mathrm{OR})_{2}$ in toluene solution [Fig. 3 (A)] the intensity of the 9-MA maximum at $389 \mathrm{~nm}$ decreased steadily, while new absorption bands increasingly developed at 452, 560, 609, 673, 700 (shoulder), 732 and $750 \mathrm{~nm}$ (shoulder). The developing UV/VIS spectrum closely resembles the reported spectra of the anthracene radical anion [21] and the spectra which were produced by pulse radiolysis of 1,2-DAE in DME [Fig. 1 (A)] as well as in DME or toluene containing $\mathrm{NaAlH}_{2}(\mathrm{OR})_{2}$ [Fig. 2 (A), (B)]. Hence it is concluded that the new absorptions belong to $\left[9-\mathrm{Ma}^{--}, \mathrm{Na}^{+}\right]$which is the single major stable product formed from 9-MA by steady-state radiolysis of the toluene solution containing $\mathrm{NaAlH}_{2}(\mathrm{OR})_{2}$. In the case of the analogous irradiation-induced reduction of pyrene to its radical anion, the formation of 
[pyrene ${ }^{--}, \mathrm{Na}^{+}$] had been additionally confirmed by its EPR spectrum [2]. The EPR and UV/VIS absorption spectra had further indicated that the aromatic radical anion/sodium cation pairs, generated by radiolysis in the presence of $\mathrm{NaAlH}_{2}(\mathrm{OR})_{2}$, form mainly solvent-separated ion pairs even in the non-polar solvent toluene [2]. This has been attributed to the complexation of the sodium counterions through the 2-methoxyethoxy substituents of $\mathrm{AlH}(\mathrm{OR})_{2}$, which is formed from $\mathrm{NaAlH}_{2}(\mathrm{OR})_{2}$ in the course of the radiationinduced reduction [reaction (16)].

The steady-state radiolysis of 1,2-DAE in toluene solution containing $\mathrm{NaAlH}_{2}(\mathrm{OR})_{2}$ differed from the corresponding experiments using 9-MA. On irradiation of the solution the band of 1,2DAE at $394 \mathrm{~nm}$ decreased in intensity and initially some $\left(1,2-\mathrm{DAE}^{--}, \mathrm{Na}^{+}\right)$is formed, showing maxima at 560, 609, 772, 687 (shoulder), 722 and 736 nm (shoulder) [Fig. 3(B), spectrum 1, obtained at a dose of $370 \mathrm{~Gy}$ ]. However, on prolonged irradiation of the solution the intensity of the spectrum of $\left(1,2-\mathrm{DAE}^{--}, \mathrm{Na}^{+}\right)$did not increase further as it was the case with $\left(9-\mathrm{MA}^{--}, \mathrm{Na}^{+}\right)$, but decreased again while simultaneously a new, somewhat broader, absorption band developed at 420 nm [Fig. 3(B), spectra 2 and 3, obtained at doses 580 and 790 Gy, respectively]. Apparently, when the initially formed $\left(1,2-\mathrm{DAE}^{--}, \mathrm{Na}^{+}\right)$reaches a sufficiently large concentration to compete with the starting material 1,2-DAE for the reducing species, e.g. $\left(\mathrm{TOL}^{--}, \mathrm{Na}^{+}\right),\left(1,2-\mathrm{DAE}^{--}, \mathrm{Na}^{+}\right)$is consumed by a consecutive reaction forming a final species. (1,2-DAE $\left.{ }^{2-}, 2 \mathrm{Na}^{+}\right)$can be ruled out as the species in question, since the blue anthracene dianion is reported to have an absorption band at $613 \mathrm{~nm}$ [21]. Also the benzylic sodium compound (9-anthryl)methyl sodium, which is the cleavage product obtained by alkali metal reduction of 1,2DAE in ether solvents, has to be disregarded, since for the corresponding potassium compound $\left[(9-\mathrm{A}) \mathrm{CH}_{2}{ }^{-}, \mathrm{K}^{+}\right]$three absorption maxima at 470 , 675 and $720 \mathrm{~nm}$ have been reported [8]. Hence, this leaves to propose sodium hydrido[(9-anthryl)methyl]bis(2-methoxyethoxy)aluminate, $\left[(9-\mathrm{A}) \mathrm{CH}_{2} \mathrm{AlH}(\mathrm{OR})_{2}{ }^{-}, \mathrm{Na}^{+}\right]$as the major final species produced by prolonged radiolysis of 1,2DAE in toluene containing $\mathrm{NaAlH}_{2}(\mathrm{OR})_{2}$.

The formation of $\left[(9-\mathrm{A}) \mathrm{CH}_{2} \mathrm{AlH}(\mathrm{OR})_{2}{ }^{-}, \mathrm{Na}^{+}\right]$ is rationalized by reactions (23) to (26):

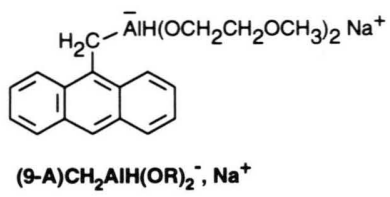

$$
\begin{aligned}
& \text { 1,2-DAE } \underset{\text { or }\left(\mathrm{Na}^{+}, \mathrm{e}_{\mathrm{s}}^{-}\right)}{\left.\stackrel{\mathrm{TOL}^{-}}{{ }^{+}}\right)}\left(1,2-\mathrm{DAE}^{--}, \mathrm{Na}^{+}\right) \\
& \left(1,2-\mathrm{DAE}^{\cdot-}, \mathrm{Na}^{+}\right) \quad \stackrel{\left(\mathrm{TOL}^{--}, \mathrm{Na}^{+}\right)}{\underset{\text { or }\left(\mathrm{Na}^{+}, \mathrm{e}_{\mathrm{s}}^{-}\right)}{\longrightarrow}} \\
& \left(1,2-\mathrm{DAE}^{2-}, 2 \mathrm{Na}^{+}\right) \\
& \left(1,2-\mathrm{DAE}^{2-}, 2 \mathrm{Na}^{+}\right) \rightarrow 2\left[(9-\mathrm{A}) \mathrm{CH}_{2}{ }^{-}, \mathrm{Na}^{+}\right] \\
& {\left[(9-\mathrm{A}) \mathrm{CH}_{2}{ }^{-}, \mathrm{Na}^{+}\right]+\mathrm{AlH}(\mathrm{OR})_{2} \rightarrow} \\
& {\left[(9-\mathrm{A}) \mathrm{CH}_{2} \mathrm{AlH}(\mathrm{OR})_{2}{ }^{-}, \mathrm{Na}^{+}\right]}
\end{aligned}
$$

The reaction between 1,2-DAE and the reducing species, e.g. the toluene radical anion/sodium cation pair $\left(\mathrm{TOL}^{-}, \mathrm{Na}^{+}\right)$in the case of toluene or, when the solvents THF or DME are used, the sodium cation/electron pair $\left(\mathrm{Na}^{+}, \mathrm{e}_{\mathrm{s}}{ }^{-}\right)-$leads to the radical anion and consecutively to the dianion [reactions (23) and (24)], the latter being able to undergo the cleavage reaction (25) yielding two (9-anthryl)methyl anion/sodium cation pairs. These form sodium aluminate salts [reaction (26)] with $\mathrm{AlH}(\mathrm{OR})_{2}$ generated in the reduction of electronically excited toluene or 1,2-DAE [reactions (19), (22) and (16)] as well as in the scavenging reactions (13) to (16). Since the aluminium-carbon bond is covalent in character [27], the species $\left[(9-\mathrm{A}) \mathrm{CH}_{2} \mathrm{AlH}(\mathrm{OR})_{2}{ }^{-}, \mathrm{Na}^{+}\right]$is expected to possess UV/VIS absorptions not at essentially longer wavelengths than those exhibited by a 9-substituted anthracene unit. The absorption maximum at $420 \mathrm{~nm}$ observed on prolonged radiolysis seems to fulfill this expectation. The proposed assignment of the final species is further supported by the product studies (see below).

\section{Product studies by steady-state irradiation}

For product studies, solutions of $5 \times 10^{-4} \mathrm{~mol}$ $\mathrm{dm}^{-3} 1,2-\mathrm{DAE}$ and $1 \mathrm{~mol} \mathrm{dm}{ }^{-3} \mathrm{NaAlH}_{2}(\mathrm{OR})_{2}$ in toluene were irradiated with ${ }^{60} \mathrm{Co} \gamma$-rays $(13.2 \mathrm{kGy}$ $\mathrm{h}^{-1}$ ) for $c a .1$ to $30 \mathrm{~min}$, respectively. The irradiated solutions were hydrolyzed to decompose the organometallic species present and the excess of $\mathrm{NaAlH}_{2}(\mathrm{OR})_{2}$, then extracted with toluene, and the toluene extracts analyzed by GC via added standards ( $n$-tetradecane and $n$-docosane). Fig. 4 
shows typical product-dose-curves obtained by plotting the product yields versus the applied dose.

Apart from the starting material 1,2-DAE, the product from $\mathrm{C}-\mathrm{C}$ bond cleavage, 9-methylan-

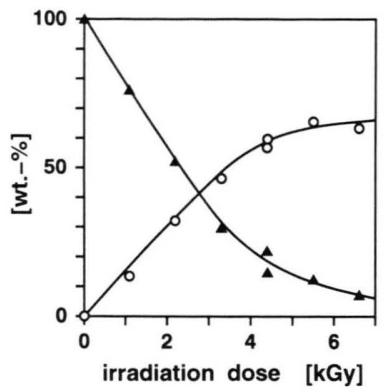

Fig. 4. ${ }^{60} \mathrm{Co} \gamma$-radiation-induced decomposition of 1,2DAE $\left(5 \times 10^{-4} \mathrm{~mol} \mathrm{dm}^{-3}\right)$ in the presence of $\mathrm{NaAlH}_{2}(\mathrm{OR})_{2}\left(1 \mathrm{~mol} \mathrm{dm}^{-3}\right)$ in toluene. Product vs. dose curves were obtained by GC analysis of toluene extracts of the irradiated and subsequently hydrolysed samples. A: 1,2-DAE; O: 9-MA.

thracene (9-MA), was the only significant product detected by GC. On prolonged irradiation 1,2DAE was consumed steadily, and, after a dose of ca. $6 \mathrm{kGy}$ had been applied, more than $90 \%$ of the compound were decomposed. The yield of 9-MA increased steadily up to $65 \%$ [wt. \% of the total material as determined by GC via the added standards]. However, it must be emphasized that 9MA results after hydrolysis. In the case of the corresponding irradiation-induced cleavages of 1,2DNE and 1,2-DPE, this has been unambiguously proven by decomposing the irradiated solutions with [D]ethanol, whereupon $\left[\mathrm{D}_{1}\right]$-1-methylnaphthalene and $\left[\mathrm{D}_{1}\right]-1$-methylpyrene, respectively, were identified by GC-MS [1,2]. Hence, one must conclude that, similarly to the cases of 1,2-DNE and 1,2-DPE, the primary cleavage product of 1,2DAE is an organometallic species which contains the (9-anthryl)methyl carbanionic fragment $\mathrm{C}_{14} \mathrm{H}_{9} \mathrm{CH}_{2}^{-}$, referred to as (9-A) $\mathrm{CH}_{2}^{-}$. The product studies and the above UV/VIS spectroscopic arguments led us to propose

$\left[(9-\mathrm{A}) \mathrm{CH}_{2} \mathrm{AlH}(\mathrm{OR})_{2}{ }^{-}, \mathrm{Na}^{+}\right]$as the cleavage product, from which 9-MA is released on hydrolysis:

$$
\left[(9-\mathrm{A}) \mathrm{CH}_{2} \mathrm{AlH}(\mathrm{OR})_{2}^{-}, \mathrm{Na}^{+}\right] \stackrel{\underset{\text { 9-MA }}{(9-\mathrm{A}) \mathrm{CH}_{3}}}{\stackrel{\mathrm{H}^{+}\left(\mathrm{H}_{2} \mathrm{O}\right)}{\longrightarrow}}
$$

\section{Conclusions}

The radiation-induced $\mathrm{C}-\mathrm{C}$ bond cleavage of the ethano link in 1,2-diarylethanes by means of aluminium hydride reagents has been studied using 1,2-DAE as the substrate, after previously already 1,2-DNE and 1,2-DPE had been investigated. The anthracene chromophor turned out to be excellently suited for pulse radiolysis studies since its absorption range enabled the detection of the transients not superimposed by absorptions of the $\mathrm{NaAlH}_{2}(\mathrm{OR})_{2}$ present in high concentration. Furthermore, the well-documented UV/VIS spectroscopic properties of the anthracene radical anion, dianion, excited triplet state molecule, and of 9-anthrylmethyl potassium $\left(9-\mathrm{ACH}_{2}^{-}, \mathrm{K}^{+}\right)$provided a safe basis for assigning the transients. Hence, new evidence could be given in support of our previous proposal that $\mathrm{NaAlH}_{2}(\mathrm{OR})_{2}$ is operating according to two different mechanisms in the polar ether solvents (THF or DME) and in the non-polar solvent toluene. Product studies through steady-state radiolysis $\left({ }^{60} \mathrm{Co} \gamma\right.$-rays $)$ of solutions of 1,2-DAE in toluene containing $\mathrm{NaAlH}_{2}(\mathrm{OR})_{2}$ resulted in symmetric $\mathrm{C}-\mathrm{C}$ bond cleavage of the ethano link, yielding after hydrolysis up to $65 \% 9$-methylanthracene (9-MA). It is very intriguing that in the $\mathrm{NaAlH}_{2}(\mathrm{OR})_{2}$-toluene system polycyclic arenes are reduced by unselective excitation with ionizing radiation to form very selectively their radical anion/sodium cation pairs, and that on prolonged irradiation in this system the radical anions of 1,2-DAE and other 1,2diarylethanes are further reduced to dianions which are capable of undergoing a selective $\mathrm{C}-\mathrm{C}$ bond cleavage reaction. In our view, the application of radiation chemistry to non-aqueous organometallic systems might offer new potentials.

\section{Acknowledgment}

This work was made possible by the generous support and continuing interest of Prof. Dr. G. Wilke. We thank Prof. Dr. D. Schulte-Frohlinde and Prof. Dr. K. Schaffner, Max-Planck-Institut für Strahlenchemie, Mülheim a. d. Ruhr, for providing the facilities for the pulse radiolysis and the ${ }^{60} \mathrm{Co} \gamma$-irradiations. The contributions of $\mathrm{B}$. Nöring, F. Sagheb (GC) and F. Reikowski (technical assistance) are gratefully acknowledged. One of us (S. S.) thanks the Ludwig-Boltzmann-Institut für Strahlenchemie und Strahlenbiologie, Wien, for financial support. 
[1] Part 1: M. W. Haenel, U.-B. Richter, S. Solar, N. Getoff, J. Chem. Soc., Faraday Trans. 86, 311 (1990).

[2] Part 2: S. Solar, N. Getoff, M. W. Haenel, U.-B. Richter, J. Chem. Soc., Faraday Trans. 89, 891 (1993).

[3] N. Berkowitz: The Chemistry of Coal; Coal Science and Technology, Vol. 7, Elsevier, Amsterdam (1985).

[4] M. W. Haenel, Fuel 71, 1211 (1992).

[5] M. M. Roy, Fuel 42, 125 (1963).

[6] J. W. T. Spinks, R. J. Woods: An Introduction to Radiation Chemistry, 3. Ed., Chapt. 9, Wiley, New York (1990).

[7] A. Lagendijk, M. Szwarc, J. Am. Chem. Soc. 93, 5359 (1971).

[8] J. M. Pearson, D. J. Williams, M. Levy, J. Am. Chem. Soc. 93, 5478 (1971).

[9] L. Schanne, M. W. Haenel, Tetrahedron Lett. 1979, 4245.

[10] C. J. Collins, H.-P. Hombach, B. Maxwell, M. C. Woody, B. M. Benjamin, J. Am. Chem. Soc. 102, 851 (1980).

[11] E. Grovenstein (Jr.), A. M. Bhatti, D. E. Quest, D. Sengupta, D. Van Derveer, J. Am. Chem. Soc. 105, 6290 (1983).

[12] L. M. Stock, in M. L. Gorbaty, J. W. Larsen, I. Wender (ed.): Coal Science 1, p. 161, Academic Press, New York (1982); and literature cited therein.

[13] M. W. Haenel, U.-B. Richter, H. Hiller, Angew. Chem. 97, 340 (1985); Angew. Chem., Int. Ed. Engl. 24, 342 (1985); and literature cited.

[14] N. Getoff, S. Solar, M. W. Haenel, Radiat. Phys. Chem. 26, 317 (1985).

[15] N. Getoff, M. W. Haenel, K. Hildenbrand, U.-B. Richter, S. Solar, Z. Naturforsch. 45 a, 157 (1990).

[16] K. C. Schreiber, W. Emerson, J. Org. Chem. 31, 95 (1966).
[17] N. Getoff, F. Schwörer, Radiat. Res. 41, 1 (1970).

[18] R. H. Schuler, L. K. Patterson, E. Janata, J. Phys. Chem. 84, 2088 (1980).

[19] H. Fricke, E. J. Hart, in F. H. Attix, W. C. Roesch, E. Tochilin (ed.): Radiation Chemistry, Vol. II, Instrumentation, p. 167, Academic Press, New York (1966).

[20] N. Getoff, in K. Kaindl, E. H. Graul (ed.): Strahlenchemie - Grundlagen, Technik und Anwendung, p. 226, Dr. A. Hüthig Verlag, Heidelberg (1967).

[21] D. E. Paul, D. Lipkin, S. I. Weissman, J. Am. Chem. Soc. 78, 116 (1956); P. Balk, G. J. Hoijtink, J. W. H. Schreurs, Rec. Trav. Chim. Pays-Bas 76, 813 (1957); J. W. Dodd, J. Chem. Soc. (B) 1971, 2427; K. Suga, S. Aoyagui, Bull. Chem. Soc. Jpn. 45, 1375 (1972); T. Shida, S. Iwata, J. Am. Chem. Soc. 95, 3473 (1973); H. Hiratsuka, H. Nakamura, Y. Tanizaki, K. Nakajima, Bull. Chem. Soc. Jpn. 55, 3407 (1982)

[22] I. Carmichael, G. L. Hug, J. Phys. Chem. Ref. Data 15, 1 (1986); J. I. del Barrio, J. R. Rebato, F. M. G.Tablas, J. Mol. Spectrosc. 132, 238 (1988); T. G. Pavlopoulos, Spectrochim. Acta 47 A, 517 (1991).

[23] G. A. Salmon, Int. J. Radiat. Phys. Chem. 8, 13 (1976).

[24] J. R. Langan, G. A. Salmon, J. Chem. Soc., Faraday Trans. I, 78, 3645 (1982).

[25] O. Štrouf, B. Čásenský, V. Kubánek, J. Organomet. Chem. Library 15, Elsevier, Amsterdam (1985); J. Vit, Vitride Reducing Agent, Technical Information Bulletin, Hexcel Corporation, Zealand, MI 49464, USA (1979).

[26] G. A. Salmon, W. A. Seddon, J. W. Fletcher, Can J. Chem. 52, 3259 (1974).

[27] K. Ziegler, H. Lehmkuhl, in Houben-Weyl-Müller: Methoden der Organischen Chemie, Vol. 13/4, Thieme, Stuttgart (1970). 